\title{
COVER CROPPING TO IMPROVE CLIMATE RESILIENCE
}

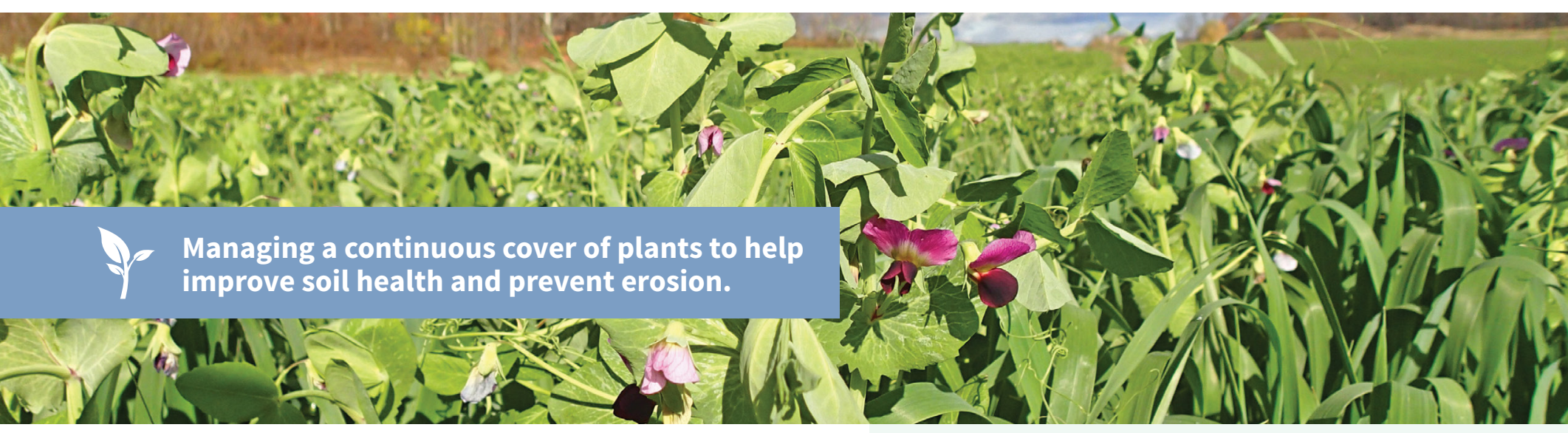

\section{Is your field covered from impacts?}

Heavy rains are becoming more frequent across the Northeastern United States and increasing soil erosion and nutrient runoff problems. Wetter weather in the spring and fall is reducing the number of days that fields can be worked.

Consider planting cover crops to help adapt to these climate trends. Compared to leaving soil bare between cash cropping periods, continuously growing plants in a field provides many benefits. These benefits can bring greater crop production stability and profitability to a farm. Cover crops increase soil organic matter, and improve soil fertility by capturing excess nutrients after a crop is harvested. They also raise soil moisture holding capacity, help prevent soil erosion, limit nutrient runoff, reduce soil compaction, and can even help suppress some pests.

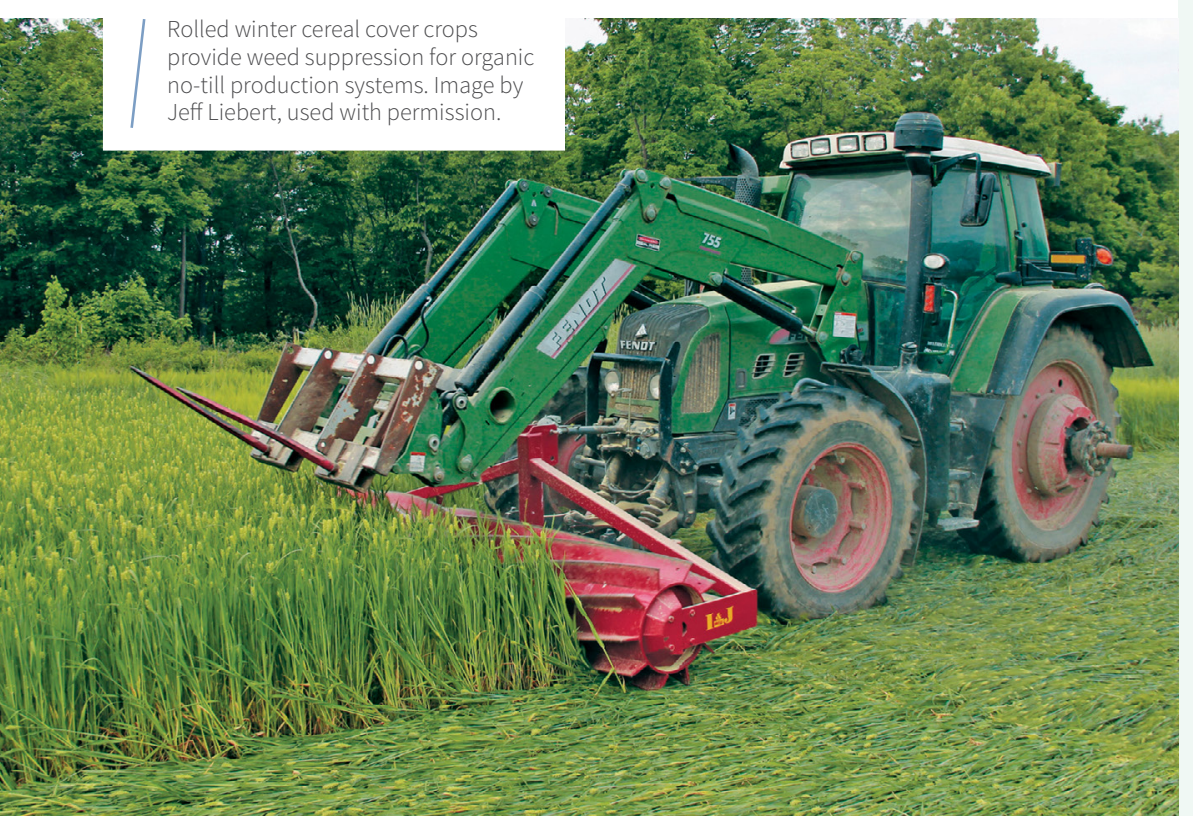

\section{Uncover the Benefits} Decomposing cover crops help feed soil life and con-
tribute to stable soil organic matter, which improves nutrient cycling and soil structure.

- Cover crop organic matter can help join soil particles into stable aggregates. These aggregates and cover crop root channels help soils better absorb intense rain, resist erosion, and improve water holding capacity in drier conditions.

Plant cover helps intercept and lessen the force of

$0 \quad$ raindrops. This reduces soil erosion, compaction, and nutrient runoff from intense rainstorms.

$\because$ Cover crops reduce water pollution risks and remove $\mathrm{CO}_{2}$ from the atmosphere. They help the environment and reduce a farm's carbon footprint.

Cover crops provide economic benefits. They can increase crop yields, reduce machinery costs, out-compete weeds, break disease and insect cycles, host beneficial organisms, attract pollinators, scavenge nutrients, and supply forage.

Cover crops take up excess water, which can help dry out wet fields before planting.

\section{Careful Considerations}

$\$$

Seed, fuel, and planting costs may not offset the economic benefits of cover crops in the short-term, but greater benefits are often experienced in the long term.

Cover crops may immobilize nitrogen or deplete soil moisture, causing yield loss in the subsequent crop.

Climate, management, and genetics affect the degree and duration of benefits from cover crops.

Some cover crops may be difficult to terminate, go to seed, and become a weed if not properly managed. 


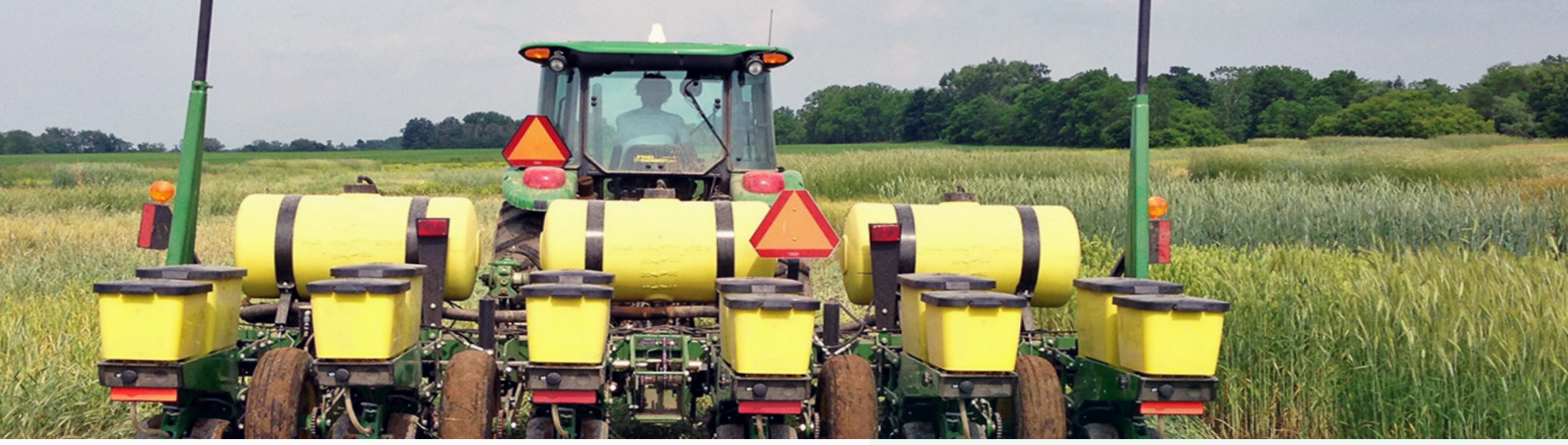

\section{Application Methods and Tips}

The first step is to decide what you want to address with cover crops, then select covers that meet those needs. For example, a grass or brassica cover crop may provide excellent nutrient scavenging, while legumes provide new nitrogen. Yet both can help protect soil against erosion. If you are just starting out with this practice, the best approach is to start small. Plant some test strips, or use small fields, and see how it works out. From there, you can adjust the timing, species, and planting method until you find a combination that works on your soils with your management style and rotation selections. The timing of establishment can greatly influence a cover crop's tolerance to the cold, wet conditions in the fall. Consider establishing them earlier to help covers overwinter better.

Information is available from University Extension, USDA Service Centers, Conservation Districts, and crop consultants. Or schedule a time to host a knowledgeable advisor to visit your farm. They will be able to help you refine your current and future plans to develop climate adaptive cropping systems. It can be useful to attend regionally specific workshops and meetings to network with farmers and agricultural professionals to learn about the latest cover crop research. You may also want to speak with your Conservation District or Extension personnel to see if there are options for borrowing planting equipment to prevent large up-front investments.

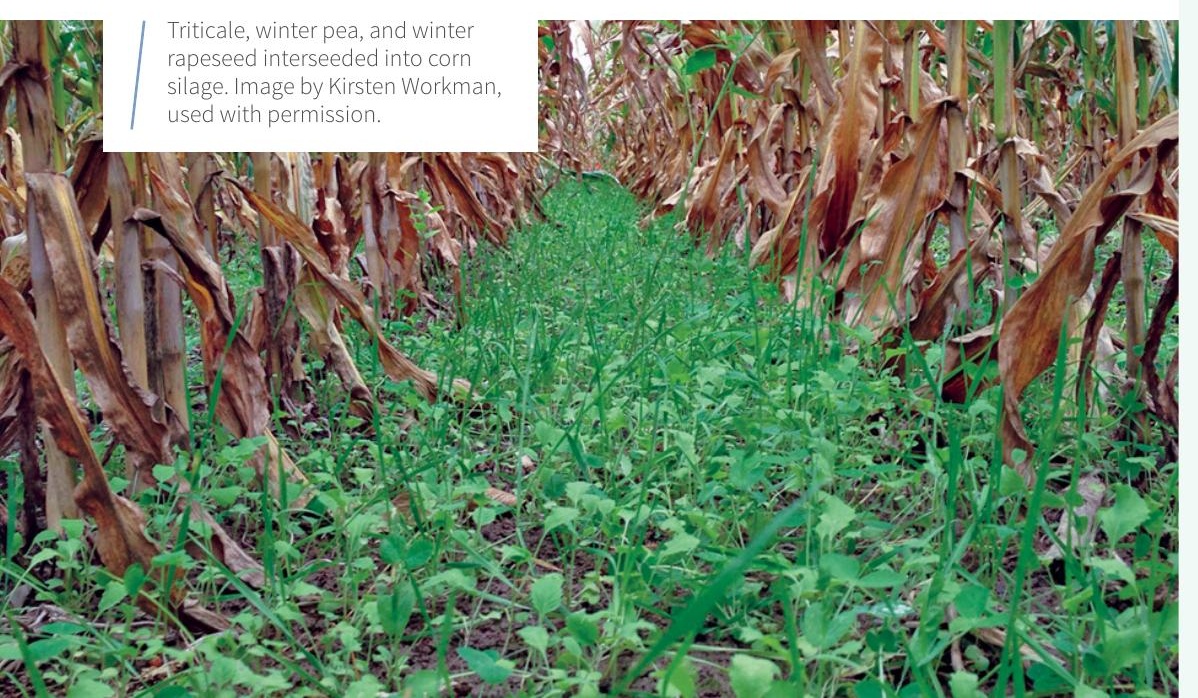

\section{Additional Resources}

USDA NRCS COVER CROP ECONOMIC TOOLS + GUIDES

»https://go.usa.gov/xnMK8

» https://go.usa.gov/xnMK9

»https://go.usa.gov/xnMKX

USDA ARS COVER CROP CHART

»https://go.usa.gov/xnMKA

\section{SUSTAINABLE AGRICULTURE RESEARCH AND EDUCATION (SARE)}

»http://bit.ly/SARECoverCrops

\section{CORNELL UNIVERSITY}

» http://covercrop.org

\section{EXTENSION}

»http://bit.ly/eXtensionCoversOrganic

»http://bit.ly/eXtensionWinterCovers

OREGON TILTH: COVER CROP (340)

IN ORGANIC SYSTEMS

» http://bit.ly/PACoverCropGuide

\section{PENNSYLVANIA STATE UNIVERSITY EXTENSION}

»http://bit.ly/PSUForageFood

» http://bit.ly/PSURollersGrain

» http://bit.ly/PSUOrganicCropGuide

» http://bit.ly/PSUAgronomyGuide

\section{UNIVERSITY OF VERMONT EXTENSION}

» https://www.uvm.edu/extension/nwcrops

\section{WWW.CLIMATEHUBS.OCE.USDA.GOV/NORTHEAST}

NEHUB@FS.FED.US

@USDACLIMATEHUBS

USDA IS AN EQUAL OPPORTUNITY PROVIDER, EMPLOYER, AND LENDER

Photo: No-till planting soybean in rolled winter cereal cover crops. Image by Jeff Liebert, used with permission. 